\title{
Influenza Illness and Partial Vaccination in the First Two Years of Life
}

\author{
Abram L. Wagner ${ }^{1}$ (D), Lionel Gresh ${ }^{2}$ (D), Nery Sanchez ${ }^{2,3}$, Guillermina Kuan ${ }^{2,3}$, John Kubale ${ }^{1}$ (D), Roger Lopez ${ }^{2,4}$, \\ Sergio Ojeda ${ }^{2,3}$, Eduardo Azziz-Baumgartner ${ }^{5}$, Angel Balmaseda ${ }^{2,4}$ and Aubree Gordon ${ }^{1, *(D)}$ \\ 1 Department of Epidemiology, School of Public Health, University of Michigan, 1415 Washington Heights, \\ Ann Arbor, MI 48109, USA; awag@umich.edu (A.L.W.); jkubale@umich.edu (J.K.) \\ 2 Sustainable Sciences Institute, Managua 14007, Nicaragua; lionel.gresh@gmail.com (L.G.); \\ nerysanchez@icsnicaragua.org (N.S.); drakuan@yahoo.com.mx (G.K.); influenzacndr@minsa.gob.ni (R.L.); \\ sojeda@icsnicaragua.org (S.O.); abalmaseda@minsa.gob.ni (A.B.) \\ 3 Centro de Salud Sócrates Flores Vivas, Ministry of Health, Managua 12014, Nicaragua \\ 4 Laboratorio Nacional de Virología, Centro Nacional de Diagnóstico y Referencia, Ministry of Health, \\ Managua 16064, Nicaragua \\ 5 Influenza Division, Centers for Disease Control and Prevention, Atlanta, GA 30333, USA; eha9@cdc.gov \\ * Correspondence: gordonal@umich.edu
}

check for updates

Citation: Wagner, A.L.; Gresh, L.; Sanchez, N.; Kuan, G.; Kubale, J.;

Lopez, R.; Ojeda, S.; Azziz-

Baumgartner, E.; Balmaseda, A.;

Gordon, A. Influenza Illness and

Partial Vaccination in the First Two

Years of Life. Vaccines 2021, 9, 676

https: / / doi.org/10.3390/

vaccines 9060676

Academic Editor: Ralph A. Tripp

Received: 25 May 2021

Accepted: 16 June 2021

Published: 20 June 2021

Publisher's Note: MDPI stays neutral with regard to jurisdictional claims in published maps and institutional affiliations.

Copyright: (c) 2021 by the authors. Licensee MDPI, Basel, Switzerland. This article is an open access article distributed under the terms and conditions of the Creative Commons Attribution (CC BY) license (https:/ / creativecommons.org/licenses/by/ $4.0 /)$.

\begin{abstract}
More information about influenza in low- and middle-income countries could guide the establishment of pediatric influenza vaccine programs. This study (1) characterizes the burden of influenza in infants, and (2) compares signs and symptoms by prior influenza vaccination or influenza illness. Newborns from Managua, Nicaragua, were followed for two years. Data came from primary medical appointments, PCR testing, and parents' daily symptom diaries. Logistic regression models estimated associations between preceding vaccination or illness and influenza incidence. Linear models compared duration of illness by prior vaccination or influenza illness. Among 833 infants, $31 \%$ had PCR-positive influenza, and $28 \%$ were vaccinated against influenza. Four $(<0.5 \%)$ were fully vaccinated. Overall, influenza incidence was 21.0 (95\% confidence interval (CI): 18.8, 23.2) per 100 person-years. Incidence was lower among those with prior influenza compared with those without preceding illness or vaccination (OR: $0.64,95 \%$ CI: $0.44,0.94)$. Partially vaccinated children had 1 day less fever than those without prior illness or vaccination $(p=0.049)$. A large proportion of children $<2$ years in Nicaragua contract influenza. Illness was attenuated for those partially vaccinated. Since few children were fully vaccinated, future studies will need to consider the effectiveness of a two-dose vaccination schedule.
\end{abstract}

Keywords: vaccine effectiveness; human influenza; fever; hospitalization; vaccination

\section{Introduction}

Infection with influenza virus can cause a variety of respiratory symptoms, and in its most severe presentation, influenza can result in acute lower respiratory infection, hospitalization, and death. Worldwide, there are between 291,243 and 645,832 deaths associated with seasonal influenza each year [1]. Children aged $<5$ years are at higher risk for complications and severe disease than older children and young adults [2]. Annually, there are an estimated 90 million new influenza cases [3] and between 9243 and 105,690 influenzaattributed deaths among children aged $<5$ years [1]. While the epidemiology of influenza has been well characterized in high income countries, $82 \%$ of influenza-attributed deaths among children occur in low- and middle-income countries (LMICs) [4]. Moreover, historically, most studies of influenza vaccine efficacy and effectiveness occur in high income countries [5].

Lack of information about the burden of influenza illness can limit the introduction of influenza vaccines in countries [6]. Within the United States, where the influenza burden and benefits of vaccination have been well characterized, the Advisory Committee on 
Immunization Practices currently recommends all individuals aged $\geq 6$ months receive an annual influenza vaccination [7]. Likewise, the World Health Organization recommends certain high risk groups, including children aged 6 months to 5 years, receive influenza vaccination [2]. Nevertheless, influenza vaccines can be expensive, especially for LMICs and among children aged 6 months to 8 years who require two doses in their first year of vaccination [8]. More information about the epidemiology of influenza illness and the benefits of influenza vaccination would help guide investment in influenza vaccination in LMICs $[9,10]$. It is particularly important to understand the burden of influenza in a place like Nicaragua, where we previously found low perceived knowledge of influenza among mothers and relatively low intent to accept an influenza vaccine for their children [11].

Modeling studies suggest Nicaragua has a substantive burden of influenza [1]. Like many LMICs in the Americas, Nicaragua provides influenza vaccines free of charge to children 6-23 months of age to help mitigate this burden, but more information about influenza morbidity in Nicaraguan children would help policymakers understand the extent to which an influenza vaccination program is needed. It is also not known if the current program achieves full vaccination of the targeted children or if partially vaccinated children are conferred some protection against influenza illness. Using a well-defined cohort of infants in Managua, Nicaragua, who were followed for the first two years of life $[12,13]$, this report aims to (1) better characterize the burden of influenza, and (2) compare influenza incidence in children aged $<2$ years by first documented influenza exposure (i.e., partial vaccination vs. prior influenza illness).

\section{Materials and Methods}

\subsection{Study Population}

Data were collected from the Nicaraguan Influenza Birth Cohort Study, a prospective cohort of infants enrolled at $<4$ weeks of age and followed until their second birthday, and who were enrolled from September 2011 through September 2014 in District II of Managua, Nicaragua [13]. Containing a population of 6.22 million, Nicaragua is a LMIC with a gross national income per capita of USD 2130 [14]. The study was based out of the Health Center Sócrates Flores Vivas (HCSFV), which in 2014 had a catchment area of approximately 61,411 people. This area contains both middle and lower class neighborhoods in terms of income and education levels, and includes some areas of urban slums [12].

\subsection{Surveys and Sample Collection}

Data from this study came from daily symptom diaries, annual health surveys, health care visits to HCSFV, and laboratory testing [12,13]. Parents filled out daily symptom diaries, indicating whether the child had rhinorrhea, cough, or fever. In health surveys conducted at enrollment, whenever the child moves household, or annually in March or April, families filled out a questionnaire about household socioeconomic status (SES).

Study participants were offered primary health care and laboratory testing for free, and HCSFV was open every day for $24 \mathrm{~h}$. Families were encouraged to bring their child to HCSFV at the first sign of subjective fever. Study participants who came to HCSFV had all medical information systematically collected and entered into study databases. Respiratory samples were collected from infants who met at least one of the following criteria: (1) fever (temperature $\geq 37.8^{\circ} \mathrm{C}$ ) or a history of fever and either rhinorrhea or cough; (2) fever or history of fever without a defined focus; (3) severe respiratory symptoms, including apnea, stridor, nasal flaring, wheezing, chest indrawing, or central cyanosis [15]; or (4) hospitalization for apnea, stridor, nasal flaring, wheezing, chest indrawing, central cyanosis, or sepsis. Respiratory samples were collected with two nasal and oropharyngeal swabs for children aged $\geq 6$ months, and a single oropharyngeal swab for infants $<6$ months. Polyester-tipped plastic swabs were transported in tubes with $3 \mathrm{~mL}$ of viral transport medium and stored at a clinical laboratory in the HCSFV at $4{ }^{\circ} \mathrm{C}$, and were transported to the National Virology Laboratory within $16 \mathrm{~h}$ (on weekdays) or $48 \mathrm{~h}$ (on weekends or holidays). 
RNA was extracted from the swabs with a QIAamp Viral RNA Mini Kit (Qiagen Corporation, Valencia, CA, USA). Protocols from the United States Centers for Disease Control and Prevention (CDC) were followed to amplify, type, and subtype/genotype Influenza A and B viruses.

\subsection{Outcomes}

The primary outcome was laboratory-confirmed influenza, and, secondarily, the signs and symptoms associated with influenza. These signs and symptoms were abstracted from health center records. For the clinical symptom to be linked to influenza illness, the recorded date of either symptom initiation or fever initiation must have occurred 2 days prior to sample collection through to 30 days after (for pneumonia and acute otitis media) and from 2 days prior to sample collection through to 6 days after (for other symptoms: cough, rhinorrhea, vomiting, diarrhea, or rhonchi). Pneumonia was defined as cough and fast breathing ( $>60$ breaths /minute for children aged $<3$ months, $>50$ breaths $/ \mathrm{min}$ for children 3-11 months, and $>40$ breaths / min for children 12-23 months) [15]. We also summarized influenza severity into a dichotomous variable of mild vs. moderate-to-severe influenza [16], where moderate-to-severe influenza referred to influenza complicated by pneumonia, acute otitis media, or a fever $>39^{\circ} \mathrm{C}$.

Calculations for the number of days of symptoms associated with an influenza illness were based on daily symptom diaries. To calculate the number of days of symptoms associated with an influenza virus infection, we summed the number of days with a symptom in the period of two days prior to the influenza infection through to 6 days after.

\subsection{Independent Variables}

The primary independent variables were history of laboratory-confirmed influenza and influenza vaccination at least 14 days prior to the current influenza episode. All started with no history of influenza illness or vaccination but were recategorized as having a prior vaccination or a prior influenza illness if either of these events took place $\geq 14$ days prior to another influenza event throughout the time series. For infants who were both vaccinated and had a history of illness, we categorized them based on which event (vaccination or illness) occurred first.

Nicaragua typically uses a Southern Hemisphere formulation of vaccines [17]. For all years where we have information on the vaccine used within the cohort (2013-2015), HCSFV stocked the trivalent Green Cross Southern formulation of the vaccine. However, it is possible that a limited number of children received another vaccine.

Other variables were added into the tertiles of household socioeconomic status (SES) constructed through an index which included whether the household had a car, a motorcycle, tap water, freezers or refrigerators, $\leq 4$ persons per television, $\leq 2$ persons per bedroom, $\geq 1$ fan per room, a concrete, ceramic, or brick floor, along with not cooking with firewood. This method is comparable to how a wealth index is calculated in the Demographic and Health Surveys program [18]. Based on the annual surveys, we also extracted information about whether there was household crowding ( $\geq 4$ persons per bedroom), or if the mother was currently breastfeeding the child. This measure of breastfeeding included both exclusive and non-exclusive breastfeeding.

\subsection{Statistical Analysis}

Descriptive statistics were generated from participant demographic and socioeconomic data.

We included two sets of regression models in this study. The first was a longitudinal model measuring the incidence of influenza. We constructed multivariable logistic regression models with the outcome of laboratory-confirmed influenza infection with person-weeks as the denominator. We specified a mixed model with random effects per person. The main independent variable in this model was prior influenza illness or vaccination. Based on a priori considerations of confounders, we also included sex, age, household 
SES, smoker in household, household crowding, and breastfeeding status in the model. This model was limited to children $\geq 6$ months (i.e., those age-eligible for vaccination).

Additionally, using multivariable models, we presented marginal estimates for a variety of clinical and parent-reported outcomes among influenza cases. These models only included laboratory-confirmed influenza cases. The outcomes were dichotomous measures of cough, rhinorrhea, vomiting or diarrhea, rhonchi, acute otitis media, moderate-to-severe influenza, and pneumonia, using logistic regression. Continuous outcomes included days of cough, fever, and rhinorrhea, using linear regression after testing for homoscedasticity and linearity. These models included only three independent variables: age, prior influenza illness or vaccination, and influenza type/subtype. The marginal estimates represent the average proportion of influenza cases with a given clinical characteristic or the average number of days with a certain symptom.

Significance was assessed at an $\alpha=0.05$ level. All analyses used SAS version 9.4 (SAS Institute, Cary, NC, USA).

\section{Results}

In total, 833 infants were enrolled into the study, with enrollment quotas for each month between 8 September 2011, and 5 September 2014 (Table 1). Participants could be followed until their second birthday and provided 73,498 person-weeks of data. Participants provided 88 weeks of data, on average, with $75 \%$ of the sample being followed at least through to 21 months of age. Overall, 216 (26\%) had laboratory-confirmed influenza once, $38(5 \%)$ twice, and 1 three times. The most common subtype was A/H3N2 (163, 55\%), followed by A/H1N1 (50, 17\%); 82 (28\%) had a B strain. There was one A/H3N2-B/Yamagata co-infection. Most of the children $(603,72 \%)$ did not receive an influenza vaccine, and most of the rest $(226,27 \%)$ had only received one dose. Only four children $(<0.5 \%)$ were considered fully vaccinated, i.e., having received two doses within one influenza season. None of the fully vaccinated children had influenza illness in the same season they were vaccinated. Almost all infants $(806,97 \%)$ were breastfed at some point in time. Many of the infants, $75 \%$ (622), were no longer being exclusively breastfed within two weeks of enrollment.

Table 1. Characteristics of study participants in Managua, Nicaragua.

\begin{tabular}{|c|c|c|c|}
\hline Characteristic & Category & Count & Proportion \\
\hline Overall & & 833 & $100 \%$ \\
\hline \multirow{4}{*}{ Year enrolled in study } & 2011 & 82 & $10 \%$ \\
\hline & 2012 & 255 & $31 \%$ \\
\hline & 2013 & 300 & $36 \%$ \\
\hline & 2014 & 196 & $24 \%$ \\
\hline \multirow{2}{*}{ Sex } & Female & 418 & $50 \%$ \\
\hline & Male & 415 & $50 \%$ \\
\hline \multirow{3}{*}{$\begin{array}{c}\text { Household } \\
\text { socioeconomic status }^{\text {a }}\end{array}$} & Lower tertile & 327 & $39 \%$ \\
\hline & Middle tertile & 245 & $29 \%$ \\
\hline & Upper tertile & 260 & $31 \%$ \\
\hline Household crowding $^{a}$ & $\geq 4$ people per bedroom & 216 & $26 \%$ \\
\hline \multirow{3}{*}{ Age of siblings ${ }^{a}$} & $0-5$ years old & 541 & $65 \%$ \\
\hline & $6-12$ years old & 536 & $64 \%$ \\
\hline & 13-18 years old & 447 & $54 \%$ \\
\hline
\end{tabular}


Table 1. Cont.

\begin{tabular}{|c|c|c|c|}
\hline Characteristic & Category & Count & Proportion \\
\hline \multirow{7}{*}{$\begin{array}{c}\text { Age when breastfeeding } \\
\text { stopped }\end{array}$} & $<1$ month & 100 & $12 \%$ \\
\hline & $1-3$ months & 193 & $23 \%$ \\
\hline & 4-6 months & 107 & $13 \%$ \\
\hline & 7-9 months & 38 & $5 \%$ \\
\hline & 10-12 months & 79 & $9 \%$ \\
\hline & 13-15 months & 15 & $2 \%$ \\
\hline & $\geq 16$ months & 301 & $36 \%$ \\
\hline \multirow{2}{*}{ Exclusively breastfed 6 months } & Yes & 163 & $20 \%$ \\
\hline & No & 670 & $80 \%$ \\
\hline \multirow{3}{*}{$\begin{array}{c}\text { Vaccination completeness (for } 1 \\
\text { season) }\end{array}$} & Never vaccinated & 603 & $72 \%$ \\
\hline & Partially vaccinated & 226 & $27 \%$ \\
\hline & Fully vaccinated & 4 & $<0.5 \%$ \\
\hline \multirow{4}{*}{ Vaccinated against influenza } & No & 603 & $72 \%$ \\
\hline & 1 dose & 217 & $26 \%$ \\
\hline & 2 doses & 38 & $5 \%$ \\
\hline & 3 doses & 2 & $<0.5 \%$ \\
\hline \multirow{4}{*}{$\begin{array}{l}\text { Symptomatic influenza } \\
\text { infection }\end{array}$} & Never & 578 & $69 \%$ \\
\hline & 1 time & 216 & $26 \%$ \\
\hline & 2 times & 38 & $5 \%$ \\
\hline & 3 times & 1 & $<0.5 \%$ \\
\hline \multirow{3}{*}{$\begin{array}{c}\text { Preceding influenza } \\
\text { vaccination or influenza illness }\end{array}$} & $\begin{array}{l}\text { No preceding vaccination } \\
\text { or illness }\end{array}$ & 429 & $52 \%$ \\
\hline & $\begin{array}{l}\text { Vaccination prior to any } \\
\text { influenza illness }\end{array}$ & 188 & $23 \%$ \\
\hline & $\begin{array}{c}\text { Influenza illness prior to } \\
\text { any vaccination }\end{array}$ & 216 & $26 \%$ \\
\hline
\end{tabular}

a Value at baseline.

During the first two years of life, a total of 296 influenza illness episodes were recorded in 256 children ( $31 \%$ ) for a rate of 21.0 (95\% CI: 18.8, 23.2) influenza episodes per 100 personyears (Figure 1 upper panel). By age, this rate was 6.0 (95\% CI: 2.2, 9.9) episodes per 100 person-years for children $<3$ months, 12.9 (95\% CI: 7.7, 18.1) per 100 person-years for children 3-5 months, 26.0 (95\% CI: 20.9, 31.2) per 100 person-years for children 6-11 months, and 24.6 (95\% CI: 21.1, 28.2) per 100 person-years for children 12-23 months.

By one year of age $14 \%$ of children had had an influenza virus infection ( $9 \%$ with influenza A and 6\% with influenza B). By two years, this number increased to $31 \%: 21 \%$ with influenza $A$ and $9 \%$ with influenza B (Figure 1 lower panel). Across the first two years, the rate of influenza-associated pneumonia was 1.1 (95\% CI: $0.5,1.6)$ episodes per 100 person-years, the rate of moderate-to-severe influenza was $2.2(95 \% \mathrm{CI}: 1.4,3.0)$ episodes per 100 person-years, and the rate of influenza-associated hospitalization was 0.6 per 100 $(95 \%$ CI: $0.2,1.0)$ person-years. 


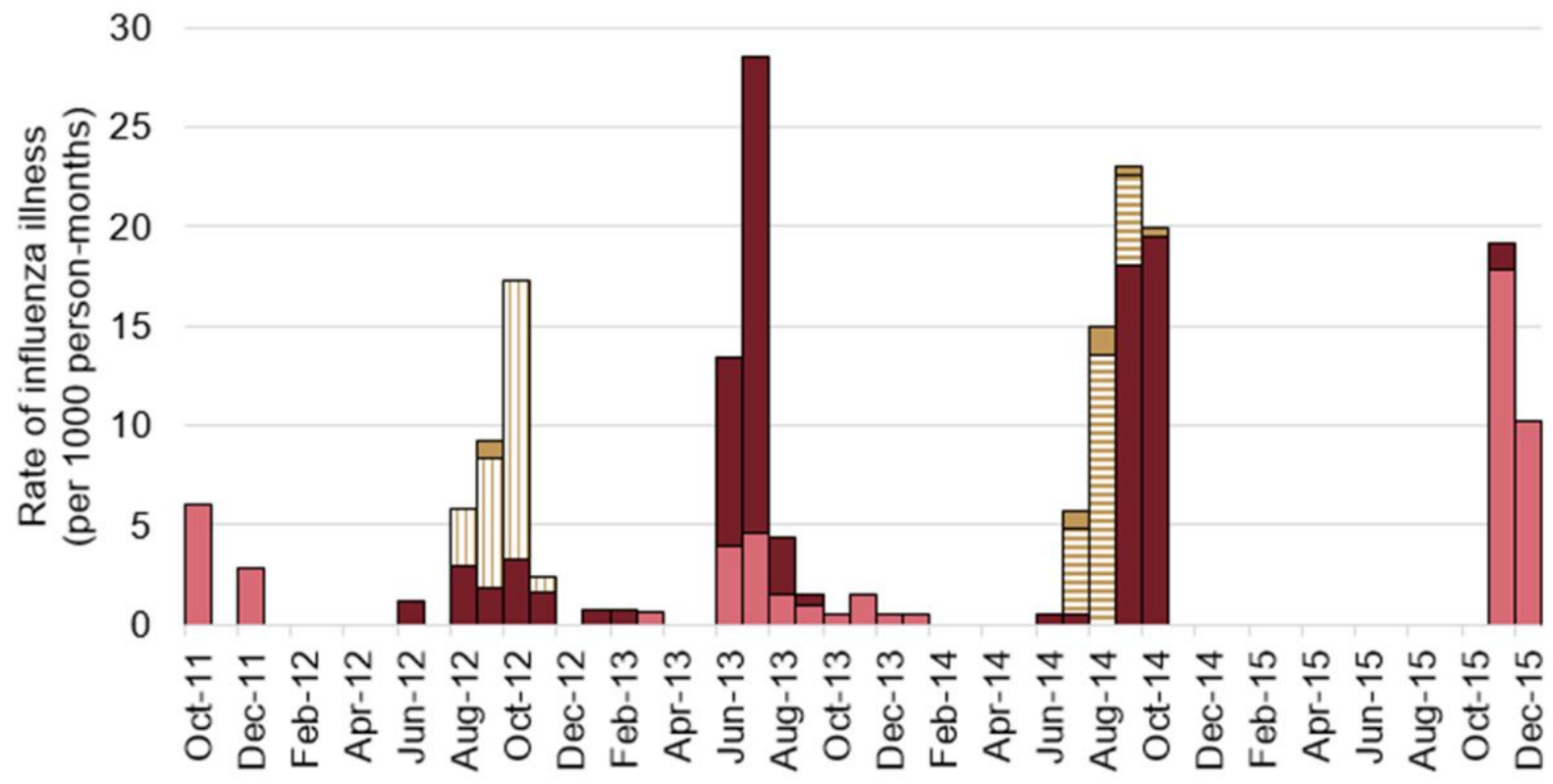

$\square \mathrm{A} / \mathrm{H} 1 \mathrm{~N} 1 \quad \square \mathrm{A} / \mathrm{H} 3 \mathrm{~N} 2 \quad \square \mathrm{B} /$ ictoria $\quad \boxminus \mathrm{B} /$ Yamagata $\quad \square \mathrm{B}$ lineage unidentified



- Any Influenza - Influenza A - - Influenza B

Figure 1. Monthly rates of influenza illness (upper panel), and cumulative proportion of influenza illness among infants $<2$ years of age in Managua, Nicaragua, 2011-2015 (lower panel). One A/H3N2-B/Yamagata co-infection during September 2014 is not portrayed.

We examined the association between influenza illness and individual and household exposures (Table 2). Compared with infants without influenza illness, those with history of a prior influenza illness had 0.64 times the odds of influenza (95\% CI: $0.44,0.94)$, but there was no difference between those with a prior (partial) vaccination. Current breastfeeding was also associated with reduced risk of influenza (OR: 0.65, 95\% CI: 0.50, 0.83). We did not observe any significant differences by sex, age, household SES, or household crowding.

Common clinical signs associated with the 295 influenza cases were cough $(80 \%)$ and rhinorrhea (81\%) (Table 3). A minority of children presented with more severe illnesses, like acute otitis media $(6 \%)$, pneumonia $(5 \%)$, or moderate-to-severe influenza $(11 \%)$. On average, cases had 3.2 days of cough, 2.0 days of fever, and 3.7 days of rhinorrhea, according 
to parent-reported symptom diaries. Duration of fever varied by prior vaccination or illness: children without a prior influenza exposure had 2.0 days of fever, compared to 1.7 days among those with a prior natural infection and 1.1 days among those previously (partially) vaccinated $(p=0.049)$.

Table 2. Logistic regression model for influenza illness incidence among children 6-23 months old in Managua, Nicaragua ( $N=53,750$ person-weeks).

\begin{tabular}{|c|c|c|c|}
\hline Characteristic & Category & OR $(95 \% \mathrm{CI})$ & $p$-Value ${ }^{a}$ \\
\hline \multirow{2}{*}{ Sex } & Male & reference & \multirow{2}{*}{0.8892} \\
\hline & Female & $1.02(0.80,1.30)$ & \\
\hline \multirow{3}{*}{ Age } & 6 to $<12$ months & $1.02(0.73,1.42)$ & \multirow{3}{*}{0.7156} \\
\hline & 12 to $<18$ months & $1.12(0.82,1.54)$ & \\
\hline & 18 to $<24$ months & reference & \\
\hline \multirow{3}{*}{$\begin{array}{c}\text { Household } \\
\text { socioeconomic status }\end{array}$} & Lower tertile & $1.04(0.77,1.40)$ & \multirow{3}{*}{0.7175} \\
\hline & Middle tertile & $0.91(0.67,1.25)$ & \\
\hline & Upper tertile & reference & \\
\hline \multirow{2}{*}{ Household crowding } & $\geq 4$ people per bedroom & $1.01(0.75,1.36)$ & \multirow{2}{*}{0.9335} \\
\hline & $<4$ people per bedroom & reference & \\
\hline \multirow{2}{*}{$\begin{array}{l}\text { Child is currently } \\
\text { breastfeeding }\end{array}$} & No & reference & \multirow{2}{*}{0.0007} \\
\hline & Yes & $0.65(0.50,0.83)$ & \\
\hline \multirow{3}{*}{$\begin{array}{c}\text { Influenza vaccination or } \\
\text { influenza illness in a } \\
\text { preceding week }\end{array}$} & $\begin{array}{l}\text { No preceding vaccination or } \\
\text { illness }\end{array}$ & reference & \multirow{3}{*}{0.0247} \\
\hline & Preceding vaccination & $1.18(0.83,1.67)$ & \\
\hline & Preceding influenza illness & $0.64(0.44,0.94)$ & \\
\hline
\end{tabular}

Table 3. Clinical and parent-reported outcomes (mean \pm standard error) by preceding vaccination or illness for 295 a influenza episodes in a cohort of children $<2$ years in Managua, Nicaragua.

\begin{tabular}{|c|c|c|c|c|c|}
\hline Characteristic & Total & Vaccinated & $\begin{array}{l}\text { Influenza } \\
\text { Illness }\end{array}$ & $\begin{array}{l}\text { No Preceding } \\
\text { Vaccination or } \\
\text { Illness }\end{array}$ & $p^{b}$ \\
\hline Overall (count) & $n=295$ & $n=43$ & $n=55$ & $n=197$ & \\
\hline Cough $^{\mathrm{c}}$ & $80 \% \pm 2 \%$ & $87 \% \pm 5 \%$ & $81 \% \pm 6 \%$ & $84 \% \pm 3 \%$ & 0.7193 \\
\hline Rhinorrhea $^{c}$ & $81 \% \pm 2 \%$ & $89 \% \pm 6 \%$ & $66 \% \pm 7 \%$ & $80 \% \pm 3 \%$ & 0.0623 \\
\hline Vomiting or diarrhea $^{c}$ & $12 \% \pm 2 \%$ & $8 \% \pm 5 \%$ & $4 \% \pm 3 \%$ & $14 \% \pm 3 \%$ & 0.0901 \\
\hline Rhonchi $^{\mathrm{c}}$ & $14 \% \pm 2 \%$ & $16 \% \pm 6 \%$ & $13 \% \pm 5 \%$ & $14 \% \pm 3 \%$ & 0.8893 \\
\hline Acute otitis media $^{c}$ & $6 \% \pm 1 \%$ & $3 \% \pm 3 \%$ & $1 \% \pm 1 \%$ & $8 \% \pm 2 \%$ & 0.1433 \\
\hline $\begin{array}{l}\text { Moderate-to-severe } \\
\text { influenza }{ }^{c}\end{array}$ & $11 \% \pm 2 \%$ & $12 \% \pm 6 \%$ & $8 \% \pm 4 \%$ & $12 \% \pm 3 \%$ & 0.6692 \\
\hline Pneumonia $^{\mathrm{c}}$ & $5 \% \pm 1 \%$ & $8 \% \pm 5 \%$ & $5 \% \pm 3 \%$ & $3 \% \pm 1 \%$ & 0.4503 \\
\hline Days of cough ${ }^{d}$ & $3.2 \pm 0.2$ & $3.1 \pm 0.5$ & $2.8 \pm 0.4$ & $3.4 \pm 0.3$ & 0.4758 \\
\hline Days of fever ${ }^{d}$ & $2.0 \pm 0.1$ & $1.1 \pm 0.3$ & $1.7 \pm 0.3$ & $2.0 \pm 0.2$ & 0.0492 \\
\hline Days of rhinorrhea ${ }^{d}$ & $3.7 \pm 0.2$ & $3.8 \pm 0.5$ & $2.9 \pm 0.4$ & $3.6 \pm 0.3$ & 0.2898 \\
\hline
\end{tabular}

${ }^{a}$ An A/H3N2-B/Yamagata co-infection is excluded. ${ }^{b}$ Marginal estimates from mixed model with random effects per person. Logistic regression model for dichotomous outcomes, linear regression model for days. All models controlled for age, history of influenza illness and vaccination, and influenza type/subtype. ${ }^{c}$ From clinical records. ${ }^{d}$ From parent-reported symptom diaries. 
Duration of cough and rhinorrhea varied by influenza type (Table 4). Cough lasted longer among influenza A cases (3.5 days for A/H1N1 and 3.4 days for $\mathrm{A} / \mathrm{H} 3 \mathrm{~N} 2$, but only 2.3 days for all influenza $\mathrm{B}, p=0.02$ ), and there was a similar pattern for rhinorrhea (4.0 days for $\mathrm{A} / \mathrm{H} 3 \mathrm{~N} 2,3.5$ days for $\mathrm{A} / \mathrm{H} 1 \mathrm{~N} 1$ and 2.9 days for influenza $\mathrm{B}, p=0.04$ ).

Table 4. Clinical and parent-reported outcomes (mean \pm standard error) by influenza type for $295^{\text {a }}$ influenza episodes in a cohort of children $<2$ years in Managua, Nicaragua.

\begin{tabular}{|c|c|c|c|c|}
\hline Characteristic & Influenza A(H1N1) & Influenza A(H3N2) & Influenza B & $p^{\mathrm{b}}$ \\
\hline Overall (count) & $n=50$ & $n=163$ & $n=82$ & \\
\hline Cough $^{\mathrm{c}}$ & $94 \% \pm 4 \%$ & $79 \% \pm 4 \%$ & $74 \% \pm 6 \%$ & 0.0589 \\
\hline Rhinorrhea $^{\mathrm{c}}$ & $76 \% \pm 7 \%$ & $86 \% \pm 3 \%$ & $77 \% \pm 6 \%$ & 0.1554 \\
\hline Vomiting or diarrhea $^{c}$ & $8 \% \pm 4 \%$ & $9 \% \pm 3 \%$ & $7 \% \pm 3 \%$ & 0.8132 \\
\hline Rhonchi $^{\mathrm{c}}$ & $23 \% \pm 7 \%$ & $14 \% \pm 3 \%$ & $9 \% \pm 3 \%$ & 0.1262 \\
\hline Acute otitis media $^{c}$ & $5 \% \pm 3 \%$ & $3 \% \pm 2 \%$ & $3 \% \pm 2 \%$ & 0.5928 \\
\hline Moderate-to-severe influenza $^{c}$ & $18 \% \pm 6 \%$ & $10 \% \pm 3 \%$ & $6 \% \pm 3 \%$ & 0.1705 \\
\hline Pneumonia $^{c}$ & $10 \% \pm 5 \%$ & $5 \% \pm 2 \%$ & $2 \% \pm 2 \%$ & 0.2265 \\
\hline Days of cough ${ }^{d}$ & $3.5 \pm 0.5$ & $3.4 \pm 0.3$ & $2.3 \pm 0.4$ & 0.0240 \\
\hline Days of fever ${ }^{d}$ & $1.5 \pm 0.3$ & $1.8 \pm 0.2$ & $1.4 \pm 0.3$ & 0.2588 \\
\hline Days of rhinorrhea ${ }^{d}$ & $3.5 \pm 0.5$ & $4.0 \pm 0.3$ & $2.9 \pm 0.4$ & 0.0385 \\
\hline
\end{tabular}

${ }^{a}$ An A/H3N2-B/Yamagata co-infection is excluded. ${ }^{b}$ Marginal estimates from mixed model with random effects per person. Logistic regression model for dichotomous outcomes, linear regression model for days. All models controlled for age, history of influenza illness and vaccination, and influenza type/subtype. ${ }^{\mathrm{c}}$ From clinical records. ${ }^{\mathrm{d}}$ From parent-reported symptom diaries.

\section{Discussion}

Through a cohort study in a well-defined population, where primary care visits were provided for free to study participants, we found that almost one-third of all children had a symptomatic PCR-positive influenza virus infection before their second birthday. We found evidence that health outcomes after influenza illness varied by previous illness and vaccination status. Almost all vaccinated children were partially, and not fully, vaccinated, indicating difficulties in implementing a two-dose vaccination program. Nevertheless, we found evidence that even partial vaccination reduced duration of influenza illness. Additionally, although not the primary focus of our analysis, we found non-exclusive breastfeeding to be protective against influenza.

We found differences in influenza outcomes by preceding influenza illness and vaccination. Those with prior documented influenza illness had a lower risk of future influenza illness, but those with a vaccination had a shorter duration of fever, suggestive of vaccineinduced disease attenuation. Nevertheless, full vaccination ( 2 doses for children in their first season they receive the vaccine) results in better protection against influenza illness [19]. Moreover, vaccination of the mother, as well as other members of the household ("cocooning"), can help prevent disease in infants $<6$ months, who are too young for vaccination [20]. Due to changes in the predominant strain of influenza by year, the vaccine formulation will change [21]. Since the $2009 \mathrm{H} 1 \mathrm{N1}$ pandemic and during the study period, the H1N1 pandemic strain co-circulated with $\mathrm{H} 3 \mathrm{~N} 2$ and B strains [22]. The low vaccine effectiveness in this study could be a function of a mismatch between the vaccine and circulating strains [23].

The overall rate of influenza in this population was similar or higher compared to other studies. The rate of influenza found in this study (21.0 per 100 person-years) was similar but slightly higher than the rate of influenza (15.5 per 100) from a preliminary analysis of this cohort study [13], possibly because of the types of influenza circulating in later years of the study. Comparatively, a study of influenza-associated illness in Peru found an incidence of 21.4 per 100 person-years among children $<2$ years [24], and 8 per 
1000 among hospitalized children aged $<6$ months and 2/1000 among children aged 6-24 months in Buenos Aires, Argentina [25].

With the exception of previous studies conducted by our research group $[13,26]$, there are few studies examining the range of clinical presentations after influenza virus infection in infants. One study from Wisconsin did contain a range of ages from children to adult [27], but many other studies focused on adults and particular populations (e.g., adults receiving transplants [28,29]), or limited their analysis to hospitalized patients. For example, studies in Kenya [30] and Rwanda [31] found that children $<1$ year had rates of influenza-associated SARI hospitalization of 0.1 and 0.3 per 100 , respectively; rates notably lower than our rate of influenza-associated hospitalization ( 0.6 per 100 person-years).

Local production of influenza vaccines in Central America and other LMICs could be valuable for several reasons. Within these areas, influenza is a substantial cause of hospitalization and deaths; with approximately 9505 hospitalizations (including 5595 children $<5$ years) and 382 deaths (including 64 in children $<5$ years) [32]. Local vaccine development could lower costs, and represent an investment in sustainable vaccination, particularly for influenza, which requires two doses for young children. Recently, a Russian pharmaceutical company has begun producing influenza vaccines in Nicaragua, and this could impact distribution of vaccines in the future. Having this vaccine product prequalified by the WHO would help procurement and regulatory review [33].

In our longitudinal analysis of influenza incidence, we controlled for breastfeeding and, in this exploratory analysis, found that breastfeeding protected against influenza illness (OR: 0.65, 95\% CI: 0.50, 0.83). Previous studies found that breastfeeding increased production of type I interferons [34]. Schlaudecker et al. found that maternal influenza vaccination could increase influenza-specific IgA levels in breastmilk, with a corresponding decrease in respiratory illness among infants who were exclusively breastfed [35]. Our study's findings offer support for a decrease in influenza illness, even among infants who were not exclusively breastfed.

\section{Strengths and Limitations}

This study has several strengths and limitations. Strengths include the longitudinal nature of the data and low loss to follow-up. We also have high confidence that we were able to catch the individual's first illness with influenza by conducting active surveillance. Another strength of this study was the use of many different data sources, from clinical records, laboratory testing, and parental symptom diaries of symptoms; however, we acknowledge that parental symptom diaries may not be as reliable as clinical sources of information. Within the US, vaccine effectiveness varied widely in this period [36], from 19\% in 2014-2015 [37] to 52\% in 2013-2014 [38]. Another limitation of this study was that a low number of children were vaccinated. These low numbers limited our ability to determine type-, subtype-, or lineage-specific vaccine effectiveness. We also did not evaluate the impact of maternal immunization or infection history.

\section{Conclusions}

This longitudinal study of influenza in infants $<2$ years found a substantial burden of disease, with relatively high rates of infection and hospitalization. A minority of children were vaccinated, while very few were fully vaccinated. We found that partial vaccination still resulted in some protection against longer duration of illness, as measured by days with fever. We would expect additional protection against influenza illness if children had received a full two-dose schedule. Strengthened influenza vaccination programs for young children could be warranted in countries, like Nicaragua, which have a high burden of illness among young children. These programs should be capable of rolling out a two-dose schedule of vaccines, and this dispersal could be aided through local production of vaccines. 
Author Contributions: Conceptualization, E.A.-B., A.B. and A.G.; Data curation, L.G., N.S., G.K. and S.O.; Formal analysis, A.L.W.; Funding acquisition, A.G.; Investigation, R.L.; Project administration, N.S., G.K. and S.O.; Software, J.K.; Writing—original draft, A.L.W.; Writing-review and editing, L.G., N.S., G.K., J.K., R.L., S.O., E.A.-B., A.B. and A.G. All authors have read and agreed to the published version of the manuscript.

Funding: This work was supported by the US Centers for Disease Control and Prevention (cooperative agreement 1U01GH000028-04) and by the National Institute of Allergy and Infectious Diseases, National Institutes of Health (contract number HHSN272201400006C).

Institutional Review Board Statement: This study was approved by the University of Michigan Health Sciences and Behavioral Sciences Institutional Review Board (\#HUM00091607) and the Nicaraguan Ministry of Health Institutional Review Board (\#NIC-MINSA/CNDR CIRE-05/05/11-029).

Informed Consent Statement: Parents or legal guardians of all participants provided written informed consent prior to enrollment.

Data Availability Statement: The data presented in this study are available on request from the corresponding author. The data are not publicly available due to personal information contained in the dataset.

Acknowledgments: The authors thank the study staff at the Health Center Sócrates Flores Vivas, the Centro Nacional de Diagnóstico y Referencia, and the Sustainable Sciences Institute for conducting the study, and the infants and their families for participating in the study.

Conflicts of Interest: The authors declare no conflict of interest. The funders had no role in the design of the study; in the collection, analysis, or interpretation of data; in the writing of the manuscript, or in the decision to publish the results.

Disclaimer: The findings and conclusions in this report are those of the authors and do not necessarily represent the official position of the US Centers for Disease Control and Prevention.

\section{References}

1. Iuliano, A.D.; Roguski, K.M.; Chang, H.H.; Muscatello, D.J.; Palekar, R.; Tempia, S.; Cohen, C.; Gran, J.M. Estimates of global seasonal influenza-associated respiratory mortality: A modelling study. Lancet 2018, 391, 1285-1300. [CrossRef]

2. World Health Organization. Influenza (Seasonal). Available online: https://www.who.int/en/news-room/fact-sheets/detail/ influenza-(seasonal) (accessed on 6 May 2021).

3. Nair, H.; Brooks, W.A.; Katz, M.; Roca, A.; Berkley, J.A.; Madhi, S.A.; Simmerman, J.M.; Gordon, A.; Sato, M.; Howie, S.; et al. Global burden of respiratory infections due to seasonal influenza in young children: A systematic review and meta-analysis. Lancet 2011, 378, 1917-1930. [CrossRef]

4. Wang, X.; Li, Y.; O’Brien, K.L.; Madhi, S.A.; Widdowson, M.A.; Byass, P.; Omer, S.B.; Abbas, Q.; Ali, A.; Amu, A.; et al. Global burden of respiratory infections associated with seasonal influenza in children under 5 years in 2018: A systematic review and modelling study. Lancet Glob. Health 2020, 8, e497-e510. [CrossRef]

5. Osterholm, M.T.; Kelley, N.S.; Sommer, A.; Belongia, E.A. Efficacy and effectiveness of influenza vaccines: A systematic review and meta-analysis. Lancet Infect. Dis. 2012, 12, 36-44. [CrossRef]

6. Bhan, M.K.; Sinha, B. Immunisation against influenza in low-income and middle-income countries. Lancet Glob. Health 2019, 7 , e827-e828. [CrossRef]

7. Grohskopf, L.A.; Liburd, L.C.; Redfield, R.R. Addressing Influenza Vaccination Disparities During the COVID-19 Pandemic. JAMA 2020, 324, 1029. [CrossRef] [PubMed]

8. Grohskopf, L.A.; Sokolow, L.Z.; Broder, K.R.; Walter, E.B.; Fry, A.M.; Jernigan, D.B. Prevention and Control of Seasonal Influenza with Vaccines: Recommendations of the Advisory Committee on Immunization Practices-United States, 2018-2019 Influenza Season. MMWR. Recomm. Rep. 2018, 67, 1-20. [CrossRef] [PubMed]

9. Howard, N.; Walls, H.; Bell, S.; Mounier-Jack, S. The role of National Immunisation Technical Advisory Groups (NITAGs) in strengthening national vaccine decision-making: A comparative case study of Armenia, Ghana, Indonesia, Nigeria, Senegal and Uganda. Vaccine 2018, 36, 5536-5543. [CrossRef]

10. Dawa, J.; Chaves, S.S.; Ba Nguz, A.; Kalani, R.; Anyango, E.; Mutie, D.; Muthoka, P.; Tabu, C.; Maritim, M.; Amukoye, E.; et al. Developing a seasonal influenza vaccine recommendation in Kenya: Process and challenges faced by the National Immunization Technical Advisory Group (NITAG). Vaccine 2018, 37, 464-472. [CrossRef] [PubMed]

11. Wagner, A.L.; Gordon, A.; Tallo, V.L.; Simaku, A.; Porter, R.M.; Edwards, L.J.; Duka, E.; Abu-Khader, I.; Gresh, L.; Sciuto, C.; et al. Intent to obtain pediatric influenza vaccine among mothers in four middle income countries. Vaccine 2020, 38, 4325-4335. [CrossRef] 
12. Gordon, A.; Kuan, G.; Aviles, W.; Sanchez, N.; Ojeda, S.; Lopez, B.; Gresh, L.; Balmaseda, A.; Harris, E. The Nicaraguan pediatric influenza cohort study: Design, methods, use of technology, and compliance. BMC Infect. Dis. 2015, 15, 504. [CrossRef]

13. Gresh, L.; Kuan, G.; Sanchez, N.; Azziz-Baumgartner, E.; Ojeda, S.; Melendez, M.; Lopez, R.; Martin, E.T.; Widdowson, M.A.; Bresee, J.; et al. Burden of Influenza and Influenza-associated Pneumonia in the First Year of Life in a Prospective Cohort Study in Managua, Nicaragua. Pediatric Infect. Dis. J. 2016, 35, 152-156. [CrossRef]

14. World Bank Nicaragua. Available online: https:/ / data.worldbank.org/country/nicaragua (accessed on 6 February 2019).

15. World Health Organization. Integrated Management of Childhood Illness Adaptation Guide: A Guide to Identifying Necessary Adaptations of Clinical Policies and Guidelines, and to Adapting the Charts and Modules for the WHO/UNICEF Course. Available online: https://www.who.int/maternal_child_adolescent/documents/pdfs/imci_adaptation_guide_2c.pdf (accessed on 13 January 2021).

16. Jain, V.K.; Rivera, L.; Zaman, K.; Espos, R.A.; Sirivichayakul, C.; Quiambao, B.P.; Rivera-Medina, D.M.; Kerdpanich, P.; Ceyhan, M.; Dinleyici, E.C.; et al. Vaccine for Prevention of Mild and Moderate-to-Severe Influenza in Children. N. Engl. J. Med. 2013, 369, 2481-2491. [CrossRef]

17. Ropero-Álvarez, A.M.; El Omeiri, N.; Kurtis, H.J.; Danovaro-Holliday, M.C.; Ruiz-Matus, C. Influenza vaccination in the Americas: Progress and challenges after the 2009 A(H1N1) influenza pandemic. Hum. Vaccines Immunother. 2016, 12, 2206-2214. [CrossRef] [PubMed]

18. The DHS Program. The DHS Program-Wealth Index Construction. Available online: http://dhsprogram.com/topics/wealthindex/Wealth-Index-Construction.cfm (accessed on 8 March 2017).

19. Sofia Arriola, C.; El Omeiri, N.; Azziz-Baumgartner, E.; Thompson, M.G.; Sotomayor-Proschle, V.; Fasce, R.A.; Von Horoch, M.; Enrique Carrizo Olalla, J.; Aparecida Ferreira de Almeida, W.; Palacios, J.; et al. Influenza vaccine effectiveness against hospitalizations in children and older adults-Data from South America, 2013-2017. A test negative design. Vaccine X 2019, 3 , 100047. [CrossRef] [PubMed]

20. Rasmussen, S.A.; Kissin, D.M.; Yeung, L.F.; MacFarlane, K.; Chu, S.Y.; Turcios-Ruiz, R.M.; Mitchell, E.W.; Williams, J.; Fry, A.M.; Hageman, J.; et al. Preparing for influenza after 2009 H1N1: Special considerations for pregnant women and newborns. Am. J. Obstet. Gynecol. 2011, 204, S13-S20. [CrossRef]

21. Hannoun, C. The evolving history of influenza viruses and influenza vaccines. Expert Rev. Vaccines 2013, 12, 1085-1094. [CrossRef]

22. Krammer, F. Influenza Primer. Nat. Rev. Dis. Prim. 2018, 460-465.e2. [CrossRef]

23. Heikkinen, T.; Ikonen, N.; Ziegler, T. Impact of influenza B lineage-level mismatch between trivalent seasonal influenza vaccines and circulating viruses, 1999-2012. Clin. Infect. Dis. 2014, 59, 1519-1524. [CrossRef] [PubMed]

24. Tinoco, Y.O.; Azziz-Baumgartner, E.; Uyeki, T.M.; Rázuri, H.R.; Kasper, M.R.; Romero, C.; Silva, M.E.; Simons, M.P.; Soto, G.M.; Widdowson, M.A.; et al. Burden of Influenza in 4 Ecologically Distinct Regions of Peru: Household Active Surveillance of a Community Cohort, 2009-2015. Clin. Infect. Dis. 2017, 65, 1532-1541. [CrossRef]

25. Marcone, D.N.; Durand, L.O.; Azziz-Baumgartner, E.; Vidaurreta, S.; Ekstrom, J.; Carballal, G.; Echavarria, M. Incidence of viral respiratory infections in a prospective cohort of outpatient and hospitalized children aged $\leq 5$ years and its associated cost in Buenos Aires, Argentina. BMC Infect. Dis. 2015, 15, 1-9. [CrossRef] [PubMed]

26. Gordon, A.; Saborío, S.; Videa, E.; López, R.; Kuan, G.; Balmaseda, A.; Harris, E. Clinical Attack Rate and Presentation of Pandemic H1N1 Influenza versus Seasonal Influenza A and B in a Pediatric Cohort in Nicaragua. Clin. Infect. Dis. 2010, 50, 1462-1467. [CrossRef] [PubMed]

27. Belongia, E.A.; Irving, S.A.; Waring, S.C.; Coleman, L.A.; Meece, J.K.; Vandermause, M.; Lindstrom, S.; Kempf, D.; Shay, D.K. Clinical Characteristics and 30-Day Outcomes for Influenza A 2009 (H1N1), 2008-2009 (H1N1), and 2007-2008 (H3N2) Infections. JAMA 2010, 304, 1091-1098. [CrossRef] [PubMed]

28. Boudreault, A.A.; Xie, H.; Choi, S.-M.; Corey, L.; Englund, J.A.; Boeckh, M. Differences in clinical outcomes after 2009 influenza A/H1N1 and seasonal influenza among hematopoietic cell transplant recipients. Blood 2011, 117, 5050-5056. [CrossRef]

29. Kumar, D.; Michaels, M.G.; Morris, M.I.; Green, M.; Avery, R.K.; Liu, C.; Danziger-Isakov, L.; Stosor, V.; Estabrook, M.; Gantt, S.; et al. Outcomes from pandemic influenza A H1N1 infection in recipients of solid-organ transplants: A multicentre cohort study. Lancet Infect. Dis. 2010, 10, 521-526. [CrossRef]

30. Widdowson, M.-A.; Emukule, G.O.; Makokha, C.; Otieno, N.A.; Nyawanda, B.; Anzala, O.; Chaves, S.S.; Njuguna, H.N.; Dawa, J.A. National burden of hospitalized and non-hospitalized influenza-associated severe acute respiratory illness in Kenya, 2012-2014. Influenza Other Respi. Viruses 2017, 12, 30-37. [CrossRef]

31. Gasana, M.; d'Arc Umuringa, J.; Kabeja, A.; Nyatanyi, T.; Tempia, S.; Nyamusore, J.; Koama, J.B.; Williams, T.; Mutagoma, M.; Mukarurangwa, A.; et al. The national burden of influenza-associated severe acute respiratory illness hospitalization in Rwanda, 2012-2014. Influenza Other Respi. Viruses 2017, 12, 38-45. [CrossRef]

32. Guzmán, G.; Méndez-Rico, J.; Cerpa, M.; Clara, W.; Aragón, A.; Palekar, R.; Lara, B.; Descalzo, M.A.; Saenz, C.; Azziz-Baumgartner, E.; et al. Estimating the burden of influenza-associated hospitalizations and deaths in Central America. Influenza Other Respi. Viruses 2016, 10, 340-345. [CrossRef]

33. Dellepiane, N.; Pagliusi, S. Opportunities for improving access to vaccines in emerging countries through efficient and aligned registration procedures: An industry perspective. Vaccine 2019, 37, 2982-2989. [CrossRef]

34. Melendi, G.A.; Coviello, S.; Bhat, N.; Zea-Hernandez, J.; Ferolla, F.M.; Polack, F.P. Breastfeeding is associated with the production of type I interferon in infants infected with influenza virus. Acta Paediatr. 2010, 99, 1517-1521. [CrossRef] 
35. Schlaudecker, E.P.; Steinhoff, M.C.; Omer, S.B.; McNeal, M.M.; Roy, E.; Arifeen, S.E.; Dodd, C.N.; Raqib, R.; Breiman, R.F.; Zaman, K. IgA and Neutralizing Antibodies to Influenza A Virus in Human Milk: A Randomized Trial of Antenatal Influenza Immunization. PLoS ONE 2013, 8, e70867. [CrossRef] [PubMed]

36. Centers for Disease Control and Prevention. Seasonal Influenza Vaccine Effectiveness, 2004-2018. Available online: https: //www.cdc.gov/flu/professionals/vaccination/effectiveness-studies.htm (accessed on 19 March 2019).

37. Zimmerman, R.K.; Nowalk, M.P.; Chung, J.; Jackson, M.L.; Jackson, L.A.; Petrie, J.G.; Monto, A.S.; McLean, H.Q.; Belongia, E.A.; Gaglani, M.; et al. 2014-2015 Influenza Vaccine Effectiveness in the United States by Vaccine Type. Clin. Infect. Dis. 2016, 63, 1564-1573. [CrossRef] [PubMed]

38. Gaglani, M.; Pruszynski, J.; Murthy, K.; Clipper, L.; Robertson, A.; Reis, M.; Chung, J.R.; Piedra, P.A.; Avadhanula, V.; Nowalk, M.P.; et al. Influenza Vaccine Effectiveness Against 2009 Pandemic Influenza A(H1N1) Virus Differed by Vaccine Type during 2013-2014 in the United States. J. Infect. Dis. 2016, 213, 1546-1556. [CrossRef] [PubMed] 